\title{
Clinical Outcomes of Patients with Coronary Artery Diseases and Moderate Left Ventricular Dysfunction: Percutaneous Coronary Intervention versus Coronary Artery Bypass Graft Surgery
}

\author{
Shaoping Wang ${ }^{1,2}$ \\ Yi Lyu ${ }^{3}$ \\ Shujuan Cheng' \\ Jinghua Liu' \\ Bijan J Borah ${ }^{2,4}$ \\ 'Department of Cardiology, Beijing \\ Anzhen Hospital, Capital Medical \\ University, Beijing, People's Republic of \\ China; ${ }^{2}$ Division of Health Care Delivery \\ Research, Mayo Clinic, Rochester, MN, \\ USA; ${ }^{3}$ Department of Anesthesiology, \\ Minhang Hospital, Fudan University, \\ Shanghai, People's Republic of China; \\ ${ }^{4}$ Robert D. and Patricia E. Kern Center \\ for Science of Health Care Delivery, \\ Mayo Clinic, Rochester, MN, USA
}

Correspondence: Bijan J Borah, Department of Health Sciences Research, Mayo Clinic, 200 First St SW, Rochester, MN, 55905, USA

Email borah.bijan@mayo.edu

Jinghua Liu

Department of Cardiology, Beijing Anzhen Hospital, Capital Medical

University, No. 2 Anzhen Road, Chaoyang

District, Beijing, 100029, People's

Republic of China

$\mathrm{Tel} / \mathrm{Fax}+861064456998$

Email liujinghua@vip.sina.com
Purpose: Percutaneous coronary intervention (PCI) and coronary artery bypass grafting $(\mathrm{CABG})$ are two revascularization strategies for patients with coronary artery disease (CAD) and left ventricular dysfunction. However, the comparisons of effectiveness between the two strategies are insufficient. This study is aimed to compare the effectiveness between PCI and CABG among patients with moderate left ventricular dysfunction.

Patients and Methods: A total of $1487 \mathrm{CAD}$ patients with moderate reduced ejection fraction $(36 \% \leq \mathrm{EF} \leq 40 \%)$, who underwent either PCI or CABG, were enrolled in a real-world cohort study (No. ChiCTR2100044378). Clinical outcomes included short- and long-term all-cause mortality, rates of heart failure (HF) hospitalization and repeat revascularization. Propensity score matching was used to balance the two cohorts.

Results: PCI was associated with lower 30-day mortality rate (hazard ratio [HR] [95\% CI], 0.35 [0.15-0.83]; $P=0.02$ ). At a mean follow-up of 4.5 years, PCI and CABG had similar allcause death (HR [95\% CI], $0.82[0.56-1.20] ; P=0.30)$ and heart failure (HF) hospitalization (HR [95\% CI], 0.93 [0.54-1.60]; $P=0.79$ ), but PCI had higher risk of repeat revascularization (HR [95\% CI], 8.62 [3.67-20.23]; $P<0.001$ ). Improvement in EF measured at 3 months later after revascularization was also similar between PCI and CABG $(P$ for interaction $=0.87)$.

Conclusion: CAD patients with moderate reduced EF who had PCI had lower short-term mortality rate but higher risk of repeat revascularization during follow-up than patients who had CABG. PCI showed comparable long-term survival, HF hospitalization risk, and EF improvement. Keywords: bypass, ejection fraction, heart failure, revascularization, stents

\section{Introduction}

Left ventricular (LV) dysfunction constitutes an independent risk factor of poor prognosis in patients with coronary artery disease (CAD). Revascularization including coronary artery bypass grafting $(\mathrm{CABG})^{1}$ and percutaneous coronary intervention $(\mathrm{PCI})^{2-4}$ may improve long-term outcomes by attenuating the ischemic state and reversing LV remodeling. ${ }^{5-7}$ However, no randomized trial compares the effectiveness of PCI and CABG in patients with $\mathrm{CAD}$ and $\mathrm{LV}$ dysfunction. ${ }^{8}$ Patients with varying extent of LV dysfunction may have different characteristics and response to treatment. ${ }^{9}$ The 2012 American College of Cardiology Foundation/American Heart Association guidelines state that magnitude of LV systolic dysfunction is one of factors for the choice of revascularization strategy. ${ }^{10}$ 
For patients with severe LV dysfunction, ie, with an ejection fraction (EF) of $35 \%$ or less, observational studies have indicated better survival with $\mathrm{CABG}$ than $\mathrm{PCI},{ }^{11-13}$ or comparable survival with $\mathrm{CABG} .{ }^{14-16}$ However, no study compares the effectiveness of PCI and CABG in patients with moderate LV dysfunction, ie, with an EF between $36 \%$ and $40 \%$.

In the present study, the effectiveness of CABG versus PCI with drug-eluting stent (DES) on short- and long-term mortality rate, HF hospitalization, and repeat revascularization was compared among patients with CAD and moderately reduced EF, using real-world data from a large hospital in China.

\section{Patients and Methods}

\section{Patient Selection and Definitions}

The study protocol was approved by the ethics committee and registered in Chinese Clinical Trial Registry (No. ChiCTR2100044378). Patients who underwent CABG or PCI with DES because of CAD in Beijing Anzhen Hospital from January 1, 2005, to December 31, 2014 were screened. Patient with an EF between 36\% and $40 \%$ assessed by echocardiography one month before PCI or CABG was included. The database created by the institution also collected the information including patient basic information, medical history, echocardiography data, electrocardiography data and therapy. The date of the procedure is called the index date. Follow-up data were acquired by medical records and phone contact. Patient selection, as well as patient attrition due to different exclusion criteria, is documented in Figure 1.

Left main disease was defined as $50 \%$ or greater diameter stenosis by visual assessment in the left main vessel. Multivessel disease was defined as the presence of stenosis $70 \%$ or greater of the coronary luminal diameter in more than 1 of the 3 major epicardial vessels.

An anatomical definition of complete revascularization was used in this analysis. Complete revascularization was defined as successful PCI (residual stenosis $<30 \%$ ) of all angiographically significant lesions (ie, $\geq 70 \%$ diameter stenosis) in 3 coronary arteries and their major branches, determined visually by the cardiologist who performed the index diagnostic catheterization procedure. A staged procedure $(\mathrm{n}=21)$ within 90 days after discharge was acceptable. For $\mathrm{CABG}$ procedures, grafting to every primary coronary artery with $70 \%$ or greater diameter stenosis was accepted as complete revascularization.
The initial echocardiography data was defined as measured within 30 days before PCI or CABG which includes EF, LV end-diastolic dimension (LVEDD), LV end-systolic dimension (LVESD), and mitral regurgitation (MR). The follow-up echocardiography data was defined as measurement reassessed at least 3 months after revascularization. ${ }^{17,18}$ For patients who had repeat echocardiography measurements, the first available measurement that was 3 months after revascularization was used. Echocardiography measurements beyond 12 months after revascularization were excluded. MR was graded semiquantitatively in an integrative manner as none/trace (0), mild (1), moderate (2), and severe (3). ${ }^{19}$

\section{Outcomes}

The primary outcomes of the study were both short-term ( $\leq 30$ days after the procedure) and long-term all-cause mortality rates. Secondary outcome measures were HF hospitalization, repeat revascularization, and cardiac death. We also assessed major adverse cardiac events as long-term all-cause death, HF hospitalization, and repeat revascularization.

A death was considered of cardiac origin unless a noncardiac cause could be identified because it was obvious. When death occurred in the index hospitalization of revascularization, it was termed cardiac death.

HF hospitalization was defined as the first readmission with a primary diagnosis of HF after discharge from the index procedure. Repeat revascularization included any unplanned repeat PCI or repeat CABG, or both. Similar to the initial procedure, a staged PCI was allowed when it was performed within 90 days after discharge and before myocardial infarction. All staged PCIs were excluded as repeat revascularization.

\section{Statistical Analysis}

Continuous variables were expressed as mean (SD) and were a comparison of the PCI cohort with the CABG cohort through use of $t$-test or 1-way analysis of variance. Cumulative incidences were estimated with Kaplan-Meier method and compared using the Log rank test. Baseline characteristics between the PCI group and the CABG group differed (Table 1). Therefore, propensity score matching was performed with use of a 1-to-1 matching protocol without replacement and a caliper width equal to 0.01 of the SD of the logit of the propensity score. ${ }^{20}$ Standardized differences were estimated for all baseline covariates before and after 
89,557 patients underwent

CABG or PCI with DES

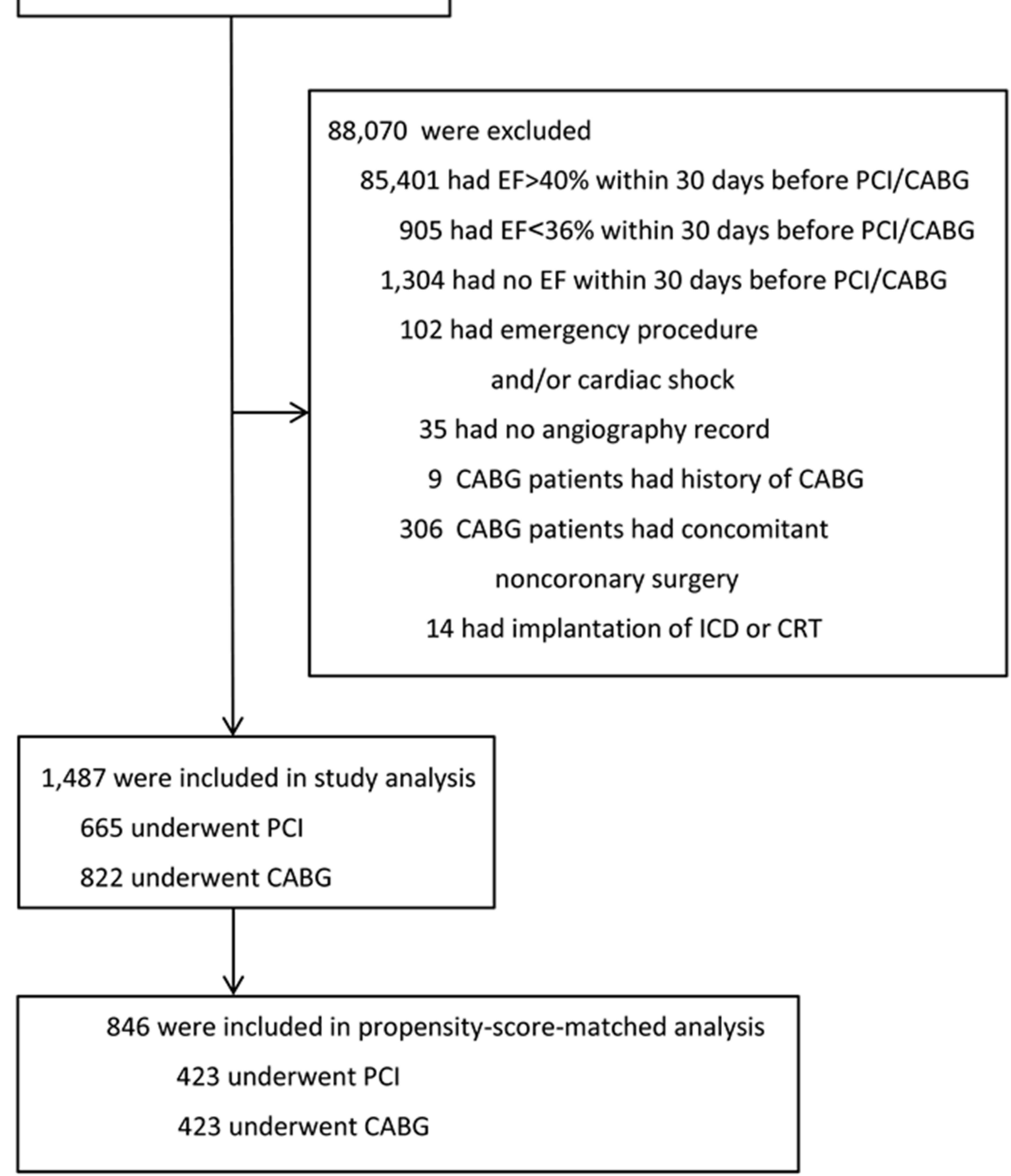

Figure I Patient selection process and study protocol. CABG indicates coronary artery bypass grafting.

Abbreviations: CRT, cardiac resynchronization therapy; DES, drug-eluting stent; EF, ejection fraction; ICD, implantable cardioverter-defibrillator; PCI, percutaneous coronary intervention.

matching. A value of less than $10.0 \%$ in standardized difference suggested balance in a given covariate between the 2 cohorts. In the matched cohort, the risks of outcomes were analyzed using a Cox proportional hazards regression model.

All statistical analyses were based on 2-tailed tests. $P$ values less than 0.05 were considered statistically significant. Statistical analyses were performed with Stata version 14.0 (StataCorp LLC).

\section{Results}

\section{Baseline Characteristics}

We identified 1487 CAD patients with an initial EF between $36 \%$ and $40 \%$ who met our inclusion criteria (Figure 1). Of these patients, $665(44.7 \%)$ underwent PCI with DES and 822 (55.3\%) underwent CABG (Table 1). Before propensity score matching, differences were observed in baseline characteristics between the 2 groups. One-to-one propensity score matching resulted in a matched sample of 846 patients 


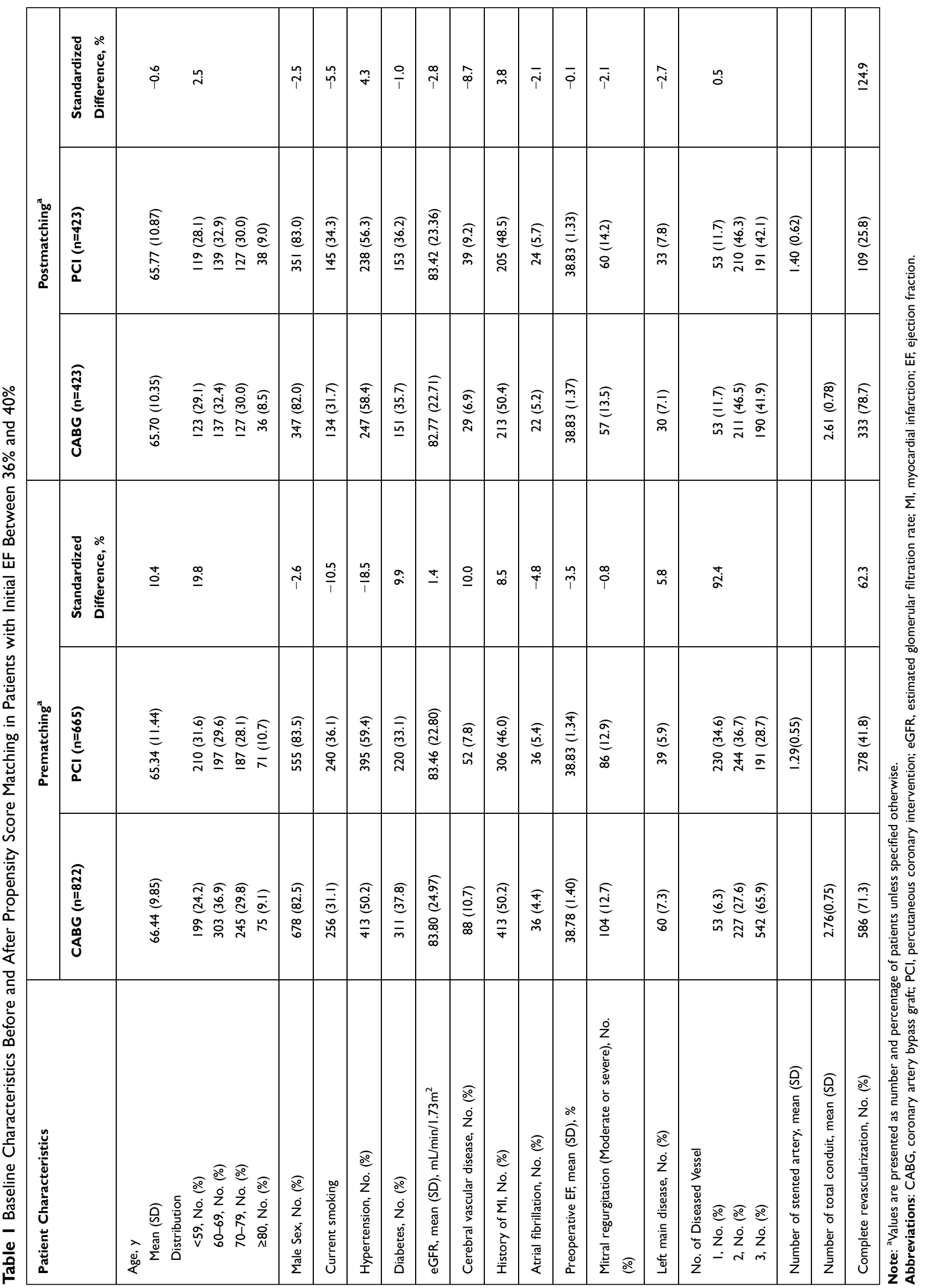



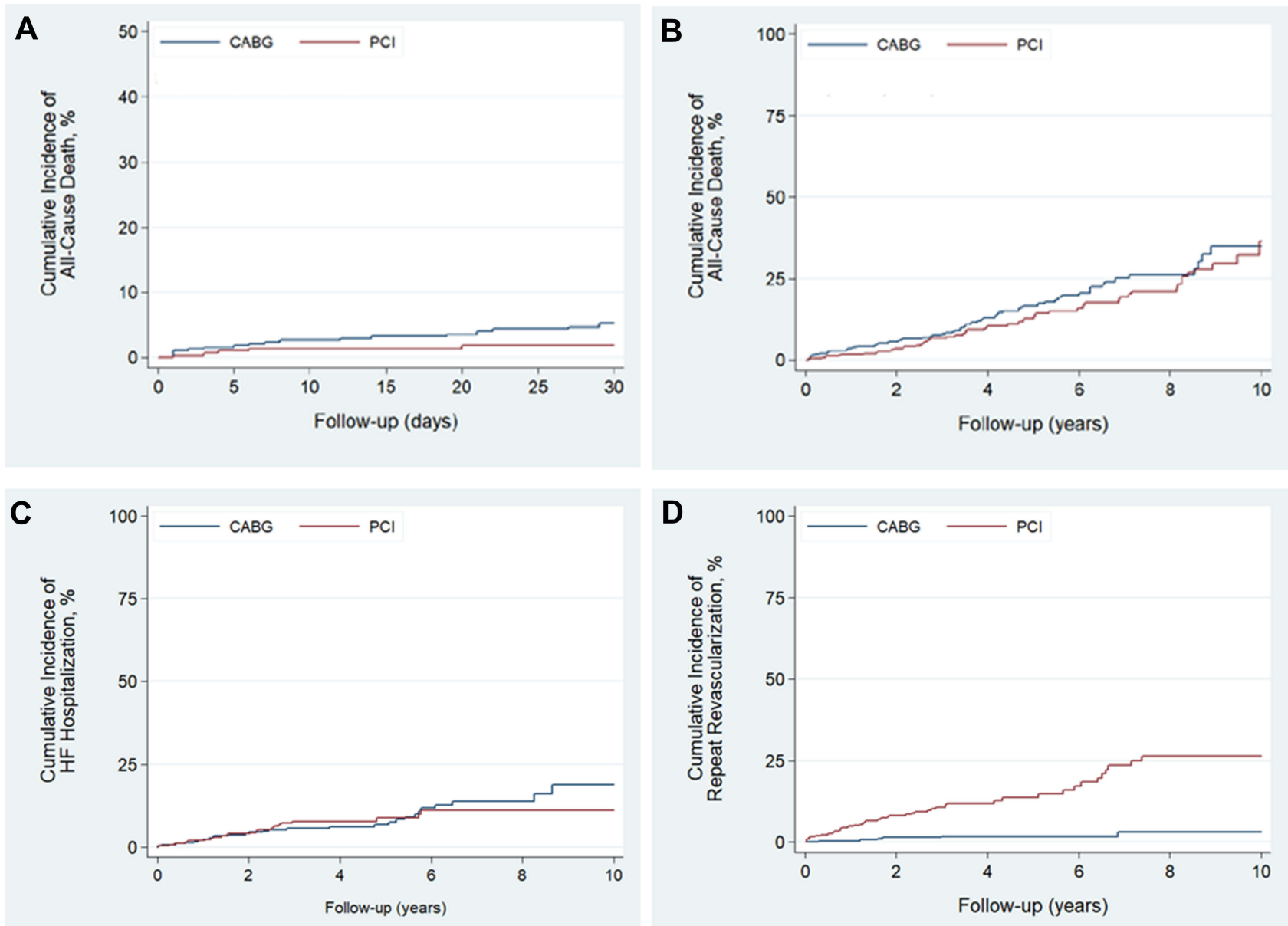

Figure 2 Percutaneous coronary intervention $(\mathrm{PCl})$ versus coronary artery bypass grafting $(\mathrm{CABG})$ for risk of short-term all-cause death $(\mathbf{A})$, long-term all-cause death (B), heart failure (HF) hospitalization (C) and repeat revascularization (D).

with 423 patients in each study cohort of PCI with DES and CABG. In the matched cohort, the proportion with complete revascularization was significantly less in the PCI group (25.8\%) than the CABG group (78.7\%) (odds ratio [OR] [95\% CI], 0.09 [0.07-0.13]; $P<0.001$ ) (Table 1).

The mean follow-up was 4.5 years (median, 3.9 years). The maximum follow-up period was 11.6 years, with $82.2 \%$ of patients completing the follow-up.

\section{Short-Term Outcomes}

There were 7 patients died within 30 days after PCI and 19 in $\mathrm{CABG}$ group. PCI was associated with lower risk of 30 day mortality (hazard ratio [HR] [95\% CI], 0.35 [0.150.83 ]; $P=0.02$ ) (Figure 2A). The risk of 30-day HF hospitalization was similar (HR [95\% CI], 0.98 [0.06-15.60]; $P=0.99)$ after PCI and CABG. No unplanned repeat revascularization occurred within 1 month for either group.

\section{Long-Term Outcomes}

PCI and CABG were associated with a similar risk of allcause death (HR [95\% CI], 0.82 [0.56-1.20]; $P=0.30$ ) (Figure 2B and Table 2). The risk of cardiac death was also similar after PCI and CABG (HR [95\% CI], 0.90 [0.59-1.37]; $P=0.61$ ) (Table 2).

No significant difference was seen in the long-term risk of $\mathrm{HF}$ hospitalization after PCI and CABG (HR [95\% CI], $0.93[0.54-1.60] ; P=0.79$ ) (Figure 2C and Table 2).

Initial treatment with PCI was associated with an increased risk of repeat revascularization (HR [95\% CI], 8.62 [3.67-20.23]; $P<0.001)$ compared with $\mathrm{CABG}$ (Figure 2D and Table 2).

The risk of major adverse cardiac events was similar after PCI and CABG (HR [95\% CI], 1.37 [1.03-1.84]; $P=0.03$ ) (Table 2). 
Table 2 Risk of Long-Term Outcomes in the Propensity Score-Matched Cohort with Preoperative EF Between 36\% and 40\%

\begin{tabular}{|c|c|c|c|c|c|}
\hline Long-Term Outcomes & No. of Patients & No. of Events & Event Rate, \%/y & Hazard Ratio $(95 \% \mathrm{Cl})$ & $P$ value \\
\hline \multicolumn{6}{|l|}{ All-cause death } \\
\hline $\mathrm{PCl}$ & 357 & 50 & 3.09 & $0.82(0.56-1.20)$ & 0.30 \\
\hline CABG & 357 & 61 & 3.76 & Reference & \\
\hline \multicolumn{6}{|l|}{ Cardiac death } \\
\hline $\mathrm{PCl}$ & 357 & 42 & 2.59 & $0.90(0.59-1.37)$ & 0.61 \\
\hline CABG & 357 & 46 & 2.83 & Reference & \\
\hline \multicolumn{6}{|l|}{ HF hospitalization } \\
\hline $\mathrm{PCl}$ & 310 & 24 & 1.80 & $0.93(0.54-1.60)$ & 0.79 \\
\hline CABG & 310 & 28 & 1.94 & Reference & \\
\hline \multicolumn{6}{|l|}{ Repeat revascularization } \\
\hline $\mathrm{PCl}$ & 315 & 45 & 3.57 & $8.62(3.67-20.23)$ & $<0.001$ \\
\hline CABG & 315 & 6 & 0.40 & Reference & \\
\hline \multicolumn{6}{|l|}{$M A_{C E}{ }^{a}$} \\
\hline $\mathrm{PCl}$ & 295 & 101 & 8.75 & $1.37(1.03-1.84)$ & 0.03 \\
\hline CABG & 295 & 84 & 6.29 & Reference & \\
\hline
\end{tabular}

Note: ${ }^{\mathrm{a}}$ Defined as all-cause death, HF hospitalization, and repeat revascularization.

Abbreviations: CABG, coronary artery bypass grafting; HF, heart failure; MACE, major adverse cardiac event; PCl, percutaneous coronary intervention.

\section{EF Improvement}

To compare EF improvement and LV remodeling after PCI and $\mathrm{CABG}$, we performed propensity score matching among 596 individuals who had echocardiography between 3 and 12 months after PCI or CABG, resulting in 178 matched pairs. Echocardiography was performed an average of 5.3 (3.2-6.9) months after PCI and 6.4 (4.89.2) months after CABG. EF was improved to a similar degree in patients treated with PCI and CABG $(P=0.87$ for interaction) (Table 3). LV size was also reduced to a similar degree in patients treated with $\mathrm{PCI}$ and $\mathrm{CABG}$ (LVESD, $P=0.85$ for interaction; LVEDD, $P=0.18$ for interaction). The severity of MR did not improve after PCI or CABG ( $P=0.44$ for interaction).

\section{Discussion}

Among CAD patients with moderate $\mathrm{LV}$ dysfunction $(36 \leq \mathrm{EF}$ $\leq 40 \%$ ) undergoing revascularization in a large cardiac care hospital in China, the patients treated with PCI had a lower 30day rate but greater risk of repeat revascularization during

Table 3 Left Ventricular Remodeling in Propensity Score-Matched Cohort of 178 Patients

\begin{tabular}{|c|c|c|c|c|}
\hline Characteristic & Baseline, Mean (SD) & Follow-Up, Mean (SD) & $P$ value & $P$ value for Interaction \\
\hline \multicolumn{5}{|l|}{$E F, \%$} \\
\hline $\mathrm{PCl}$ & $38.80(1.33)$ & $46.94(11.24)$ & $<0.001$ & 0.87 \\
\hline CABG & $38.91(1.31)$ & $47.23(10.66)$ & $<0.001$ & \\
\hline \multicolumn{5}{|l|}{ LVESD, mm } \\
\hline $\mathrm{PCl}$ & $45.11(7.38)$ & $41.85(8.82)$ & $<0.001$ & 0.85 \\
\hline CABG & $44.65(7.06)$ & $4 I .64(8.46)$ & $<0.001$ & \\
\hline \multicolumn{5}{|l|}{ LVEDD, mm } \\
\hline $\mathrm{PCl}$ & $57.89(7.37)$ & $56.83(7.84)$ & 0.03 & 0.18 \\
\hline CABG & $57.69(6.59)$ & $55.71(7.26)$ & $<0.001$ & \\
\hline \multicolumn{5}{|l|}{ MR grade } \\
\hline $\mathrm{PCl}$ & $0.93(0.79)$ & $0.89(0.78)$ & 0.53 & 0.44 \\
\hline CABG & $0.90(0.64)$ & $0.93(0.66)$ & 0.65 & \\
\hline
\end{tabular}

Abbreviations: CABG, coronary artery bypass grafting; EF, ejection fraction; LVEDD, left ventricular end-diastolic dimension; LVESD, left ventricular end-systolic dimension; $\mathrm{MR}$, mitral regurgitation; $\mathrm{PCl}$, percutaneous coronary intervention. 
follow-up compared with CABG. However, long-term mortality rate, risk of $\mathrm{HF}$ hospitalization, and $\mathrm{EF}$ improvement were similar following PCI and CABG.

The effectiveness between PCI and CABG among CAD patients has been compared for several years according to the revascularization indication and severity of coronary diseases. For patients with unprotected left main coronary artery stenosis, ${ }^{21}$ PCI resulted in comparable mortality, stroke, and MI compared with CABG. PCI was associated with higher rates of repeat revascularization. For patients with multivessel disease, ${ }^{22} \mathrm{CABG}$ was associated with lower mortality, MI and repeat revascularization. Risk-adjusted mortality temporally decreased significantly after CABG but not after PCI across all revascularization indication. ${ }^{23,24}$

For patients with $\mathrm{CAD}$ and $\mathrm{LV}$ dysfunction, regarding whether and how best to revascularize have not been clearly established. The Surgical Treatment for Ischemic Heart Failure (STICH) trial randomized 1212 patients with an EF of $35 \%$ or less to receive optimal medical therapy with or without CABG. ${ }^{25}$ The benefits of CABG were indicated. However, the first trial evaluating the role of PCI for ischemic ventricular dysfunction (REVIVED-BCIS2) ${ }^{26}$ is still underway. To date, the long-term outcomes of PCI compared with CABG have not been evaluated in randomized trial. Subgroup analysis (abnormal LV function) of a collaborative analysis of individual patient data from ten randomized trials indicated similar risk of mortality between PCI and CABG among patients with multivessel disease. ${ }^{27}$ Observational studies analyzing patients with the EF less than $36 \%, 40 \%$ or $50 \%$ had controversial results. Some studies ${ }^{11-13,28}$ have suggested survival is worse after PCI in comparison to $\mathrm{CABG}$, while others ${ }^{2,14}-16$ have demonstrated similar survival. The degree of left ventricular dysfunction is a known determinant of both short-term and long-term adverse outcome events in patients undergoing $\mathrm{CABG}^{29}$ or PCI. ${ }^{30}$ Thus our study, in contrast to previous studies, compared the effectiveness of PCI versus CABG in patients with EF among $36 \%$ to $40 \%$ only. Our findings show PCI was associated with lower risk of 30-day mortality but had similar long-term mortality rate in comparison with $\mathrm{CABG}$ in patients with moderate left ventricular dysfunction.

No randomized study has compared the outcomes of complete revascularization with incomplete revascularization in CAD patients after either PCI or $\mathrm{CABG} .{ }^{31}$ For patients with LV dysfunction, achieving complete revascularization by PCI or CABG is often not feasible due to coronary anatomical factors, patient comorbidities and procedural considerations.
Similar with other studies, ${ }^{13,14}$ in our study, the rate of complete revascularization in patients undergoing PCI was significantly lower than that in patients undergoing CABG. Complex anatomy and limitation of contrast agent administration in PCI procedure might be potential reasons. During the long-term follow-up, PCI was associated with an increased risk of repeat revascularization compared with $\mathrm{CABG}$.

Few data are available, to our knowledge, that comparing the effects of 2 revascularization strategies on EF improvement among patients with ischemic LV dysfunction. In the present study, we found that PCI was associated with similar extent of EF improvement and reverse LV remodeling as with CABG. The relative factors associated with EF recovery after revascularization need to be further investigated.

\section{Limitations}

This was a nonrandomized observational study from a single center. The follow-up date came from medical records and phone contact that was not completely followed up for all patients. Therefore, as with any other observational studies, ours might be limited from selection biases. We attempted to minimize such bias using propensity score matching. Moreover, we did not have data on both the coronary anatomical risk score (ie, Synergy Between Percutaneous Coronary Intervention With Taxus and Cardiac Surgery score), which is a useful tool to assess the risk of revascularization, and the myocardial viability test. Medications during follow-up indicate the status of optimal medical therapy for HF, which has an important effect on long-term outcome regardless of coronary revascularization strategy for patients with ischemic $\mathrm{HF}^{32}$ Our study could not incorporate any of these factors because of lack of relevant data. Thus, similar with other studies, ${ }^{11,12,14-16,28}$ these variables could not be included in analysis.

\section{Conclusion}

Among patients with moderate LV dysfunction $(36 \leq \mathrm{EF}$ $\leq 40 \%$ ), PCI with DES and CABG had similar long-term risk of death, risk of HF hospitalization, and EF improvement. However, PCI was associated with a higher risk of repeat revascularization and a lower risk of short-term death. At the expense of increased risk of repeat revascularization, PCI with DES for selected patients with moderate LV dysfunction may be an alternative to CABG.

\section{Data Sharing Statement}

The datasets are available from the corresponding author (Jinghua Liu) upon reasonable request. 


\section{Ethical Approval and Informed Consent}

The Ethics Committee of the Beijing Anzhen Hospital approved the study. All procedures performed in this study involving human participants were in accordance with the Declaration of Helsinki. Because this was a retrospective cohort study and waiver of informed consent will not adversely affect the rights and welfare of the subjects, written informed consent from the patients was waived. Patient data confidentiality was protected.

\section{Acknowledgments}

We express our gratitude to all participated staffs for completing the CRISIS Project (Coronary Revascularization In Patients with Ischemic Heart Failure and Prevention of Sudden Cardiac Death).

\section{Funding}

This work was supported by the National Basic Research Program of China (973 Program, 2015CB554404).

\section{Disclosure}

All authors declare that they have no conflict of interest.

\section{References}

1. Velazquez EJ, Lee KL, Jones RH, et al. Coronary-artery bypass surgery in patients with ischemic cardiomyopathy. $N$ Engl $J$ Med. 2016;374(16):1511-1520. doi:10.1056/NEJMoa1602001

2. Yang JH, Choi SH, Song YB, et al. Long-term outcomes of drug-eluting stent implantation versus coronary artery bypass grafting for patients with coronary artery disease and chronic left ventricular systolic dysfunction. Am J Cardiol. 2013;112(5):623-629. doi:10.1016/j.amjcard.2013.04.035

3. Lee DH, Jeong MH, Rhee JA, et al. Predictors of long-term survival in acute coronary syndrome patients with left ventricular dysfunction after percutaneous coronary intervention. Korean Circ J. 2012;42 (10):692-697. doi:10.4070/kcj.2012.42.10.692

4. Kunadian V, Pugh A, Zaman AG, Qiu W. Percutaneous coronary intervention among patients with left ventricular systolic dysfunction: a review and meta-analysis of 19 clinical studies. Coron Artery Dis. 2012;23(7):469-479. doi:10.1097/MCA.0b013e3283587804

5. Michler RE, Rouleau JL, Al-Khalidi HR, et al. Insights from the STICH trial: change in left ventricular size after coronary artery bypass grafting with and without surgical ventricular reconstruction. $J$ Thorac Cardiovasc Surg. 2013;146(5):1139-1145 e1136. doi:10.1016/j.jtcvs.2012.09.007

6. Vakil K, Florea V, Koene R, Kealhofer JV, Anand I, Adabag S. Effect of coronary artery bypass grafting on left ventricular ejection fraction in men eligible for implantable cardioverter-defibrillator. $\mathrm{Am}$ J Cardiol. 2016;117(6):957-960. doi:10.1016/j.amjcard.2015.12.029

7. Adachi Y, Sakakura K, Wada H, et al. Determinants of left ventricular systolic function improvement following coronary artery revascularization in heart failure patients with reduced ejection fraction (HFrEF). Int Heart J. 2016;57(5):565-572. doi:10.1536/ihj.16-087

8. Velazquez EJ. Percutaneous coronary intervention or coronary artery bypass grafting to treat ischemic cardiomyopathy? JAMA Cardiol. 2020;5(6):641. doi:10.1001/jamacardio.2020.0597
9. Ponikowski P, Voors AA, Anker SD, et al. 2016 ESC Guidelines for the diagnosis and treatment of acute and chronic heart failure: the Task Force for the diagnosis and treatment of acute and chronic heart failure of the European Society of Cardiology (ESC)Developed with the special contribution of the Heart Failure Association (HFA) of the ESC. Eur Heart J. 2016;37(27):2129-2200. doi:10.1093/eurheartj/ ehw128

10. Fihn SD, Gardin JM, Abrams J, et al. 2012 ACCF/AHA/ACP/AATS/ PCNA/SCAI/STS Guideline for the diagnosis and management of patients with stable ischemic heart disease: a report of the American College of Cardiology Foundation/American Heart Association Task Force on Practice Guidelines, and the American College of Physicians, American Association for Thoracic Surgery, Preventive Cardiovascular Nurses Association, Society for Cardiovascular Angiography and Interventions, and Society of Thoracic Surgeons. J Am Coll Cardiol. 2012;60(24):e44 e164. doi:10.1016/j.jacc.2012.07.013

11. Nagendran J, Norris CM, Graham MM, et al. Coronary revascularization for patients with severe left ventricular dysfunction. Ann Thorac Surg. 2013;96(6):2038-2044. doi:10.1016/j.athoracsur.2013.06.052

12. Kang SH, Lee CW, Baek S, et al. Comparison of outcomes of coronary artery bypass grafting versus drug-eluting stent implantation in patients with severe left ventricular dysfunction. Am J Cardiol. 2017;120(1):69-74. doi:10.1016/j.amjcard.2017.03.261

13. Sun LY, Gaudino M, Chen RJ, Bader Eddeen A, Ruel M. Long-term outcomes in patients with severely reduced left ventricular ejection fraction undergoing percutaneous coronary intervention vs coronary artery bypass grafting. JAMA Cardiol. 2020;5(6):631. doi:10.1001/ jamacardio.2020.0239

14. Bangalore S, Guo Y, Samadashvili Z, Blecker S, Hannan EL. Revascularization in patients with multivessel coronary artery disease and severe left ventricular systolic dysfunction: everolimus-eluting stents versus coronary artery bypass graft surgery. Circulation. 2016;133 (22):2132-2140. doi:10.1161/CIRCULATIONAHA.115.021168

15. Gioia G, Matthai W, Gillin K, et al. Revascularization in severe left ventricular dysfunction: outcome comparison of drug-eluting stent implantation versus coronary artery by-pass grafting. Catheter Cardiovasc Interv. 2007;70(1):26-33. doi:10.1002/ccd.21072

16. Toda K, Mackenzie K, Mehra MR, et al. Revascularization in severe ventricular dysfunction $(15 \%<\mathrm{OR}=\mathrm{LVEF}<\mathrm{OR}=30 \%)$ : a comparison of bypass grafting and percutaneous intervention. Ann Thorac Surg. 2002;74(6):2082-2087; discussion 2087.

17. Epstein AE, DiMarco JP, Ellenbogen KA, et al. ACC/AHA/HRS 2008 Guidelines for Device-Based Therapy of Cardiac Rhythm Abnormalities: a report of the American College of Cardiology/ American Heart Association Task Force on Practice Guidelines (Writing Committee to Revise the ACC/AHA/NASPE 2002 Guideline Update for Implantation of Cardiac Pacemakers and Antiarrhythmia Devices): developed in collaboration with the American Association for Thoracic Surgery and Society of Thoracic Surgeons. Circulation. 2008;117(21):e350-e408. doi:10.1161/CIRCUALTIONAHA.108.189742

18. Kusumoto FM, Calkins H, Boehmer J, et al. HRS/ACC/AHA expert consensus statement on the use of implantable cardioverter-defibrillator therapy in patients who are not included or not well represented in clinical trials. J Am Coll Cardiol. 2014;64 (11):1143-1177. doi:10.1016/j.jacc.2014.04.008

19. Kron IL, Acker MA, Adams DH, et al.; American Association for Thoracic Surgery Ischemic Mitral Regurgitation Consensus Guidelines Writing Committee. 2015 The American Association for Thoracic Surgery Consensus Guidelines: ischemic mitral valve regurgitation. J Thorac Cardiovasc Surg. 2016;151(4):940-956. doi:10.1016/j.jtcvs.2015.08.127

20. Borah BJ, Moriarty JP, Crown WH, Doshi JA. Applications of propensity score methods in observational comparative effectiveness and safety research: where have we come and where should we go? J Comp Eff Res. 2014;3(1):63-78. doi:10.2217/cer.13.89 
21. Sardar P, Giri J, Elmariah S, et al. Meta-analysis of drug-eluting stents versus coronary artery bypass grafting in unprotected left main coronary narrowing. Am J Cardiol. 2017;119(11):1746-1752. doi:10.1016/j.amjcard.2017.03.009

22. Hannan EL, Wu C, Walford G, et al. Drug-eluting stents vs. coronary-artery bypass grafting in multivessel coronary disease. $N$ Engl J Med. 2008;358(4):331-341. doi:10.1056/NEJMoa071804

23. Alkhouli M, Alqahtani F, Kalra A, et al. Trends in characteristics and outcomes of patients undergoing coronary revascularization in the United States, 2003-2016. JAMA Netw Open. 2020;3(2):e1921326. doi:10.1001/jamanetworkopen.2019.21326

24. Mukherjee D. Coronary revascularization in the United States-patient characteristics and outcomes in 2020. JAMA Netw Open. 2020;3(2): e1921322. doi:10.1001/jamanetworkopen.2019.21322

25. Velazquez EJ, Lee KL, Deja MA, et al. Coronary-artery bypass surgery in patients with left ventricular dysfunction. $N$ Engl J Med. 2011;364(17):1607-1616. doi:10.1056/NEJMoa1100356

26. Perera D, Clayton T, Petrie MC, et al. Percutaneous revascularization for ischemic ventricular dysfunction: rationale and design of the REVIVED-BCIS2 trial: percutaneous coronary intervention for ischemic cardiomyopathy. JACC Heart Fail. 2018;6(6):517-526. doi:10.1016/j.jchf.2018.01.024

27. Hlatky MA, Boothroyd DB, Bravata DM, et al. Coronary artery bypass surgery compared with percutaneous coronary interventions for multivessel disease: a collaborative analysis of individual patient data from ten randomised trials. Lancet. 2009;373(9670):1190-1197. doi:10.1016/S0140-6736(09)60552-3
28. Marui A, Kimura T, Nishiwaki N, et al. Comparison of five-year outcomes of coronary artery bypass grafting versus percutaneous coronary intervention in patients with left ventricular ejection fractions $<=50 \%$ versus $>50 \%$ (from the CREDO-Kyoto $\mathrm{PCI} / \mathrm{CABG}$ Registry Cohort-2). Am J Cardiol. 2014;114(7):988-996. doi:10.1016/j.amjcard.2014.07.007

29. Stahle E, Bergstrom R, Edlund B, et al. Influence of left ventricular function on survival after coronary artery bypass grafting. Ann Thorac Surg. 1997;64(2):437-444. doi:10.1016/s0003-4975(97) 00536-5

30. Mamas MA, Anderson SG, O'Kane PD, et al. Impact of left ventricular function in relation to procedural outcomes following percutaneous coronary intervention: insights from the British Cardiovascular Intervention Society. Eur Heart J. 2014;35(43):3004-3012a. doi:10.1093/eurheartj/ehu303

31. Gaba P, Gersh BJ, Ali ZA, Moses JW, Stone GW. Complete versus incomplete coronary revascularization: definitions, assessment and outcomes. Nat Rev Cardiol. 2021;18(3):155-168. doi:10.1038/ s41569-020-00457-5

32. Kurlansky P, Herbert M, Prince S, Mack M. Coronary artery bypass graft versus percutaneous coronary intervention: meds matter: impact of adherence to medical therapy on comparative outcomes. Circulation. 2016;134 (17):1238-1246. doi:10.1161/CIRCULATIONAHA.115.021183
Therapeutics and Clinical Risk Management

\section{Publish your work in this journal}

Therapeutics and Clinical Risk Management is an international, peerreviewed journal of clinical therapeutics and risk management, focusing on concise rapid reporting of clinical studies in all therapeutic areas, outcomes, safety, and programs for the effective, safe, and sustained use of medicines. This journal is indexed on PubMed Central, CAS,

\section{Dovepress}

EMBase, Scopus and the Elsevier Bibliographic databases. The manuscript management system is completely online and includes a very quick and fair peer-review system, which is all easy to use. Visit http://www.dovepress.com/testimonials.php to read real quotes from published authors. 